\title{
VARYING LEVELS OF THE DIAN LAKES AND THE DIAN LAKES CULTURE
}

\author{
Terry Lustig ${ }^{1}$, Li Kunsheng ${ }^{2}$, Jiang Zhilong ${ }^{3}$, and Chen Guo ${ }^{4}$
}

\author{
${ }^{1}$ University of Sydney, Australia; terry@environmentalmanagment.com.au \\ ${ }^{2}$ School of Humanities, Yunnan University, China; kunshengli@tom.com \\ ${ }^{3}$ Yunnan Institute of Archaeology and Cultural Relics, China; jzlong168@hotmail.com \\ ${ }^{4}$ School of Humanities, Yunnan University, China; chengshainanhai2001@sina.com
}

\begin{abstract}
Much of Yunnan's limited flat land is around the Dian Lakes. The levels of these lakes seem to have fluctuated over many metres through the millennia, and this has resulted in alterations to the extent and depth of water, the extent of surrounding flat land, and to that of land enriched by floods. Appreciating these changes could provide pointers to aspects of the cultures surrounding these lakes. First, the discovery of the occupation site near Wangjiadun, 3 to 5 metres below the current level of Dianchi Lake, indicates that the lake could have been smaller and shallower than today. From the dates and depths of cored samples, it would seem that the this habitation could have been occupied more than 4,500 years ago, and not in the early Bronze Age as has been suggested. Second, historical records indicate that the Dian kingdom was situated on thousands of square li of rich flat land around Dianchi Lake. However, through use of a digital elevation model of the area, it is determined that this area was about $800 \mathrm{li}^{2}-$ Substantially less. Even if the other major Dian Lakes-Fuxian, Xingyun and Qi Lu-are included, the total area could only be about 1,000 $l i^{2}$. This limited area of fertile land suggests that other sources of wealth, such as trade and minerals, played a greater role, and that the population was relatively small. This calls into question the nature of the socio-political structure within the Dian culture. Third, another inference from the historical record is that accelerated soil erosion resulted in the blocking of the outlet of Dianchi Lake, starting in the $13^{\text {th }}$ century. This caused extensive flooding, even around Kunming. However, hydraulic considerations suggest that erosion could not have been the cause; instead, the flooding may have been induced by some other human activity.
\end{abstract}

\section{INTRODUCTION}

Yunnan is one of China's hilliest provinces. The geological formations are highly folded and faulted, and the SichuanYunnan region is one of the most seismically active in China
(Wang et al. 1998: 5-9). Figure 1-derived from a digital elevation model (DEM) generated from rasters of the region from the CGIAR-CSI website (Jarvis et al. 2008; CIAT-CSI 2009) - shows that much of the flat land in Yunnan, where flat is taken as having no more than a $3 \%$ slope, is located at the five major Dian Lakes (Figure 2).

This flat land, a result of deposition of sediments eroded from the surrounding catchments, has been continually built up and extended further into the lakes, and in most cases the areas of the lakes have correspondingly decreased. This natural trend can be accelerated by cultural fill for land reclamation. Some sediments travel further, reaching the water and settling to the bottom, so that the lakes also tend to become smaller and shallower (Figure $3 \mathrm{a}$ ).

However, sedimentation, landslip and erosion at a lake's outlet can cause variations in the water level. If the level of the outlet lowers, it exposes more land. If it rises, the area of land tends to diminish. Nevertheless, if the rate of sedimentation or fill in the lake is sufficiently high, the area of land could still increase even if the outlet is building up, while the area of water would continue to decrease (Figure $3 b)$.

Low-lying land around a lake can be naturally fertile, where the lake and the inflowing rivers overtop their banks during floods and deposit sediment. The extent of land that is enriched in this way depends on the height and frequency of the floods. As the level of the lake rises or falls over time, the land receiving flood silt migrates up or down the slope with it. The shallower the slope of the land, the more extensively flood-nourished it would be. Conversely, if the slope is steep, the area would be reduced (Figure $3 \mathrm{c}$ ).

Such changes in water level, depth of water, and the extent of flat land around the lakes alter the environment, and that the plant and animal species most suited to the locality-both natural and farmed-- alter with it. This in turn should influence the economies of those living at and around the lakes. 
BULLETIN OF THE INDO-PACIFIC PREHISTORY ASSOCIATION 31, 2011

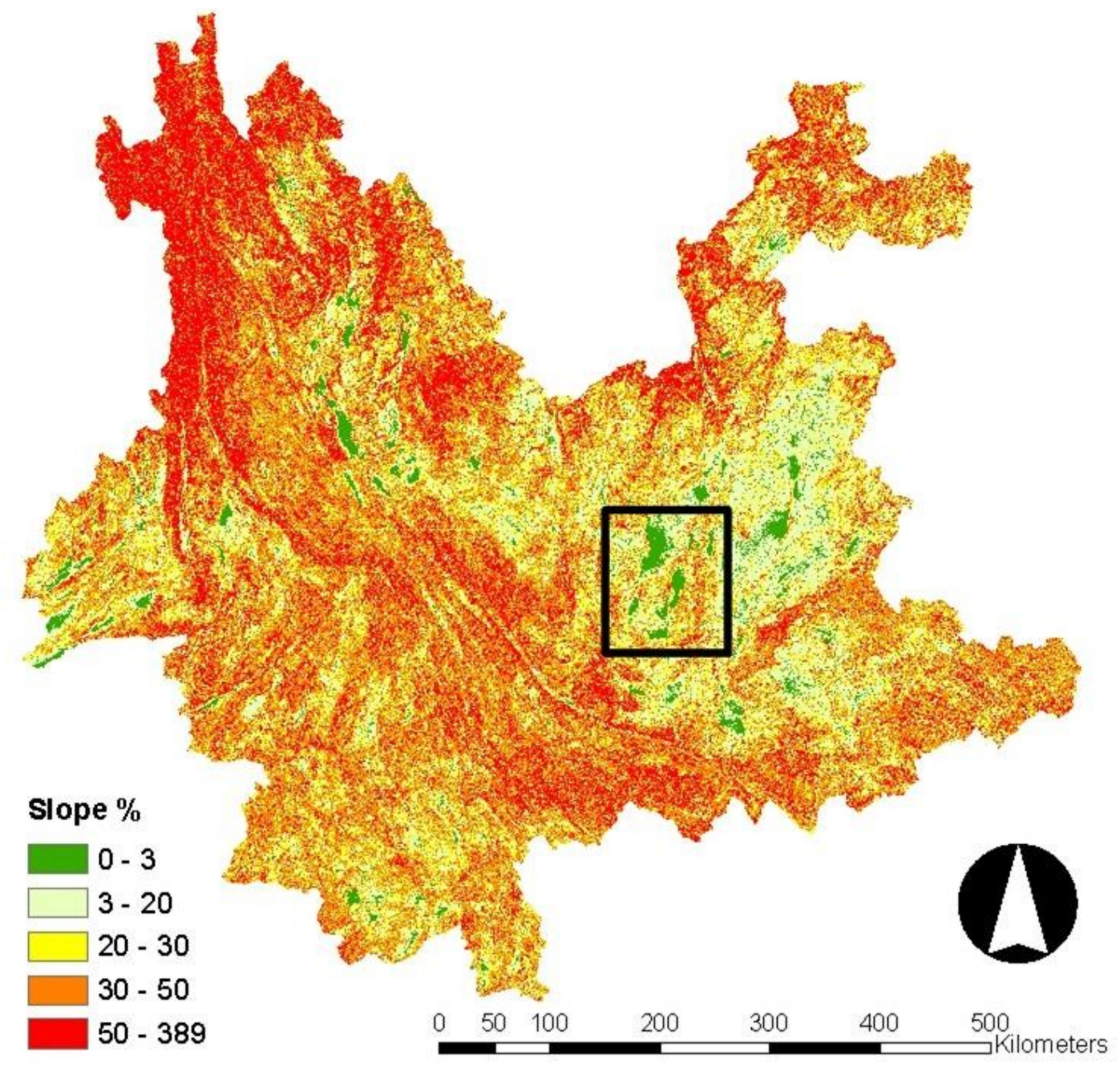

Figure 1. Distribution of slopes in Yunnan Province. Flat land is dark green. 


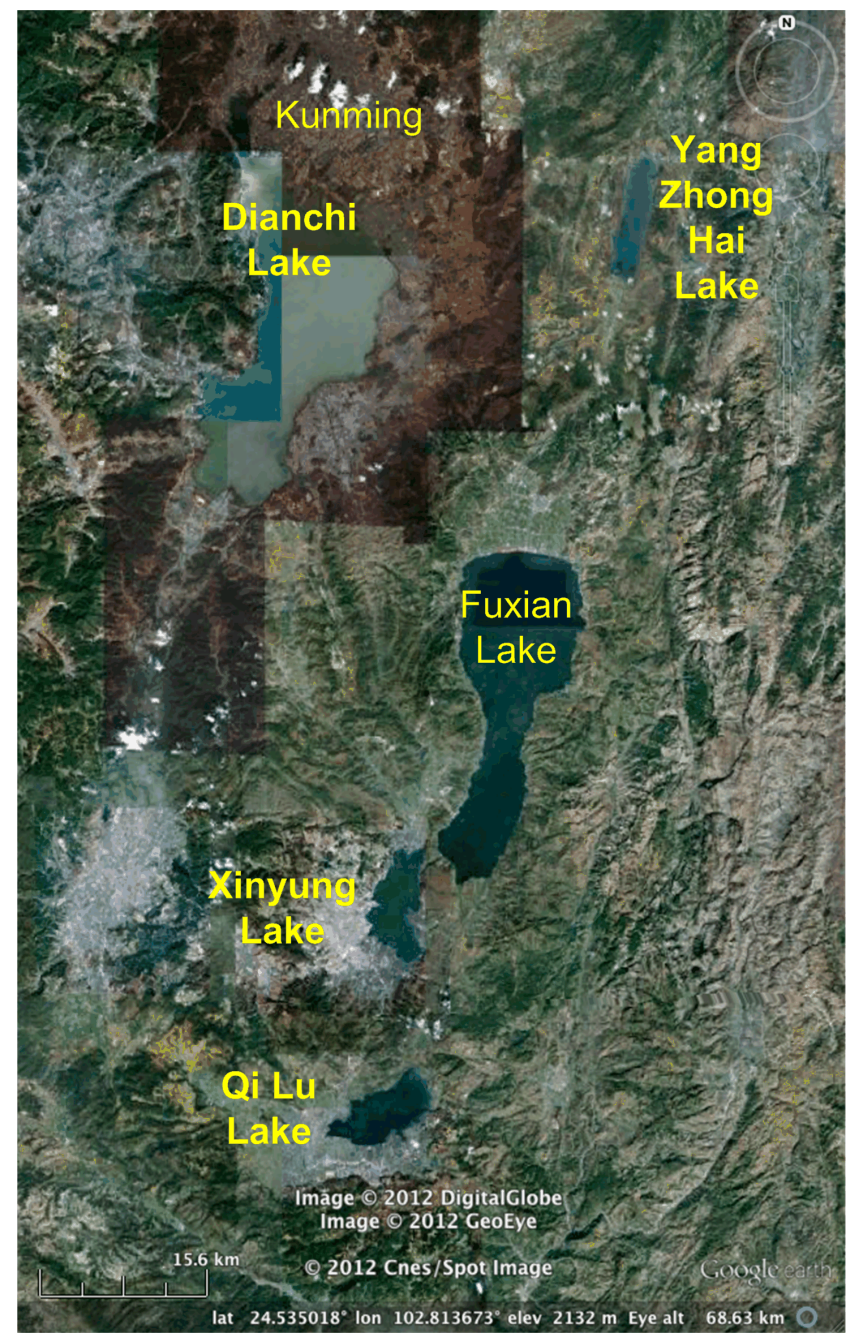

Figure 2. Dian Lakes.

Thus knowing the levels of the lakes at different times, their long- and short-term fluctuations, and the areas of flat land bounding them could illuminate aspects of the successive economies of the inhabitants. This will be illustrated with some features that have been elicited for different periods of occupation of the Dian Lakes.

\section{WANGJIADUN OCCUPATION SITE}

The largest lake, Dianchi (Figure 4) is quite shallow today, having a maximum depth of 5.7 metres (Zhu et al. 1989: 3). While the Lake was probably significantly higher and deeper before 12,000 BP (Figure 5), it appears to have lowered to near its current level some time between 10,000 BP, when the rainfall approached its current rate, and 4,000 BP, when there are hints that today's climatic seasonality becomes evident (Walker 1986: 481). Sun et al. (1986: 466-467) examined cores from boreholes in the northern part of Dianchi Lake and adjacent land areas. The pollen found- particularly in cores DZ13 and DZ18 - indicates that the northern area of Dianchi Lake was shallow or swampy from 4,500 BP to about 1,500 BP (Sun et al. 1986: 449). It is logical to infer that as sediment accumulated in this part of the Lake, the outlet accreted at the same rate.

Figure 6 sets out the information from these two cores (Sun et al. 1986: Table 1, Figs. 4, 7) together with inferred elevations of the bed of the lake at these two locations at different times. This suggests that the depth of sediment that accumulated in the period 4,500 BP to 1,500 BP was about $1 / 2$ metre. From $1,500 \mathrm{BP}$ to today, the cores indicate that there was roughly between $1 / 4$ and 1 metre of accumulation. As the tops of these two cores were, respectively, 1 and $1 \frac{1}{2}$ metres below the current level of the lake, it might be inferred that the water level today is about $2 \frac{1}{2}$ metres higher than the level of the swamp, and thus of the lake itself 4,500 years ago. In other words, the water level was roughly $2 \frac{1}{2}$ metres lower than today at 4,500 BP.

At Wangjiadun, near Kunming, an early settlement was discovered in 1977, after the land had been drained by pumping out water (Li and Wang, 1983). The site has been tentatively dated to the 11 th century BCE on the basis of the style and composition of two bronze objects: a ge or halberd, and an adze (Zhang et al. 1983: 20-22). However, since these were found without context, it is not clear that the bronzes are 3,000 years old, nor that they can be assuredly associated with this settlement, discovered after Li and Wang searched for additional information about the bronzes.

Now the DEM indicates that the Wangjiadun site could be as much as four to five metres below the current level of the lake, and GPS supports this. Li and Wang (1983) have reported that they found rows of regularly spaced wooden poles there. Jiang (2002: 238) has written that the poles were about 1.5 metres long and 0.2 metres in diameter with sharp points at one end, consistent with supports for elevated buildings (Wang, pers. comm. to Jiang). If the poles were on dry land, this would point to a water level at least four to five metres lower than today, and an occupation appreciably older than 4,500 years.

If the poles were over shallow water-for example to support a structure-the maximum practical depth for installing such poles would be no more than about a metre. The water level at the site would thus have been no less than approximately three metres lower than today. If we take this level as being reasonably consistent with the $2 \frac{1}{2} \mathrm{~m}$ level at $4,500 \mathrm{BP}$ or earlier, as suggested by the coring results, it could be hypothesised that the site at Wangjiadun may be no less than 4,500 years old. If the poles were installed on dry land, the date could have been significantly earlier. While it is possible that the Wangjiadun site could be about 3,000 years old, the available evidence suggests that it is appreciably older. Nevertheless, this finding is based on only 


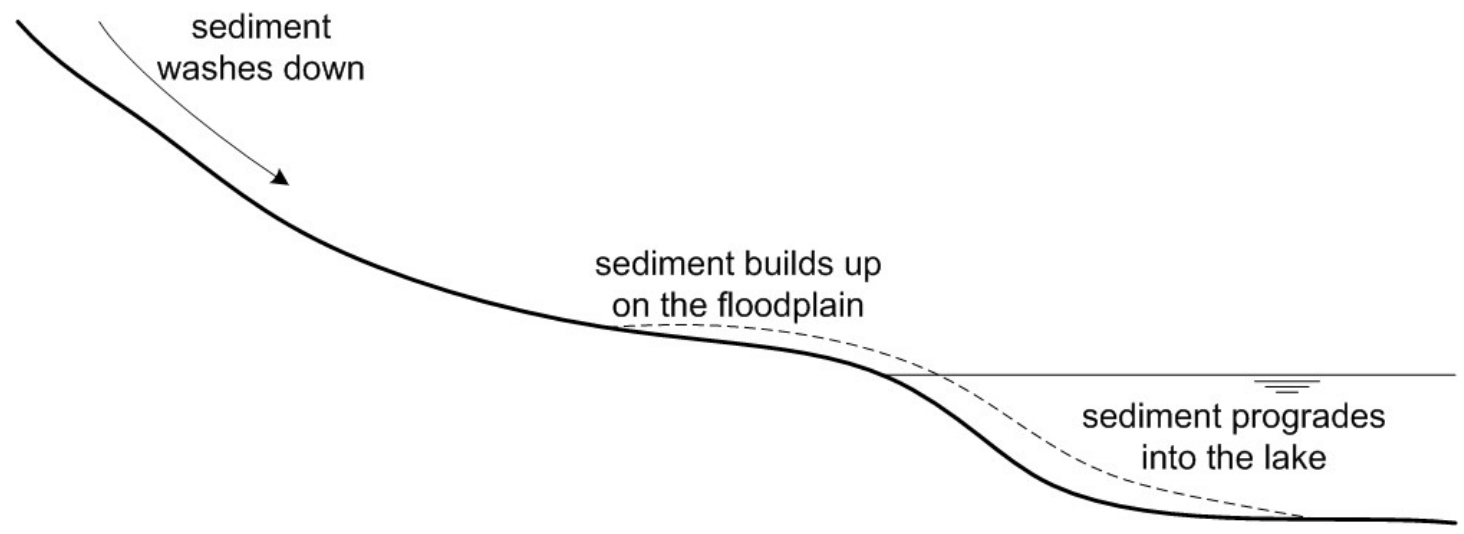

a) Sediment building up on floodplain and in lake.

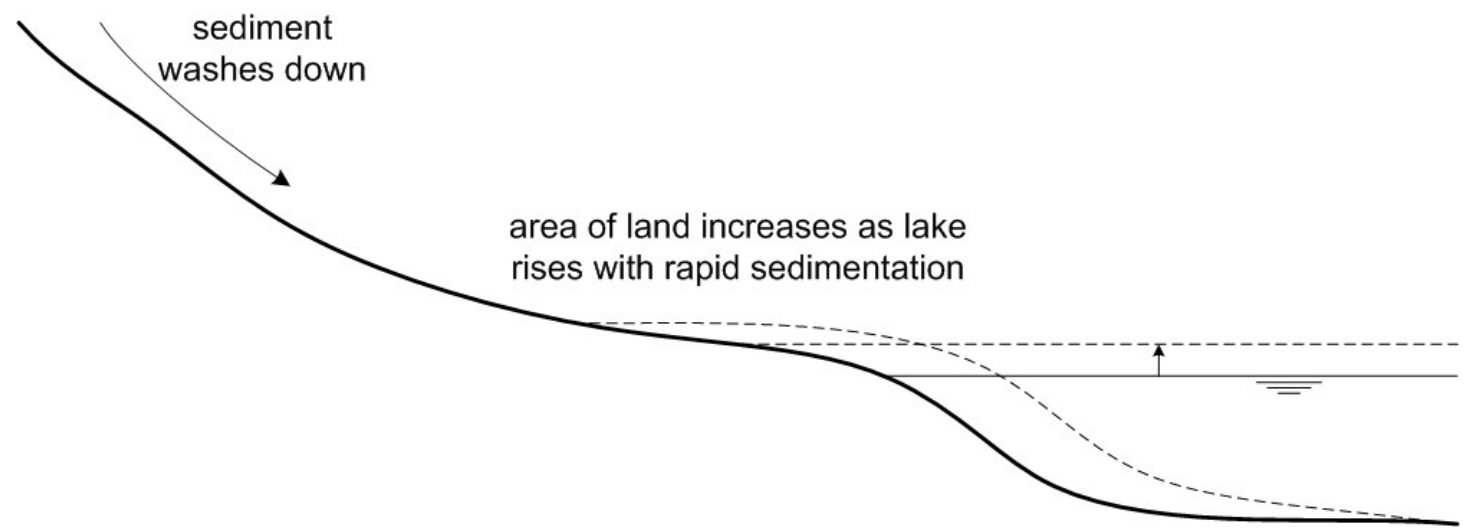

b) Area of lake decreasing despite water level rising

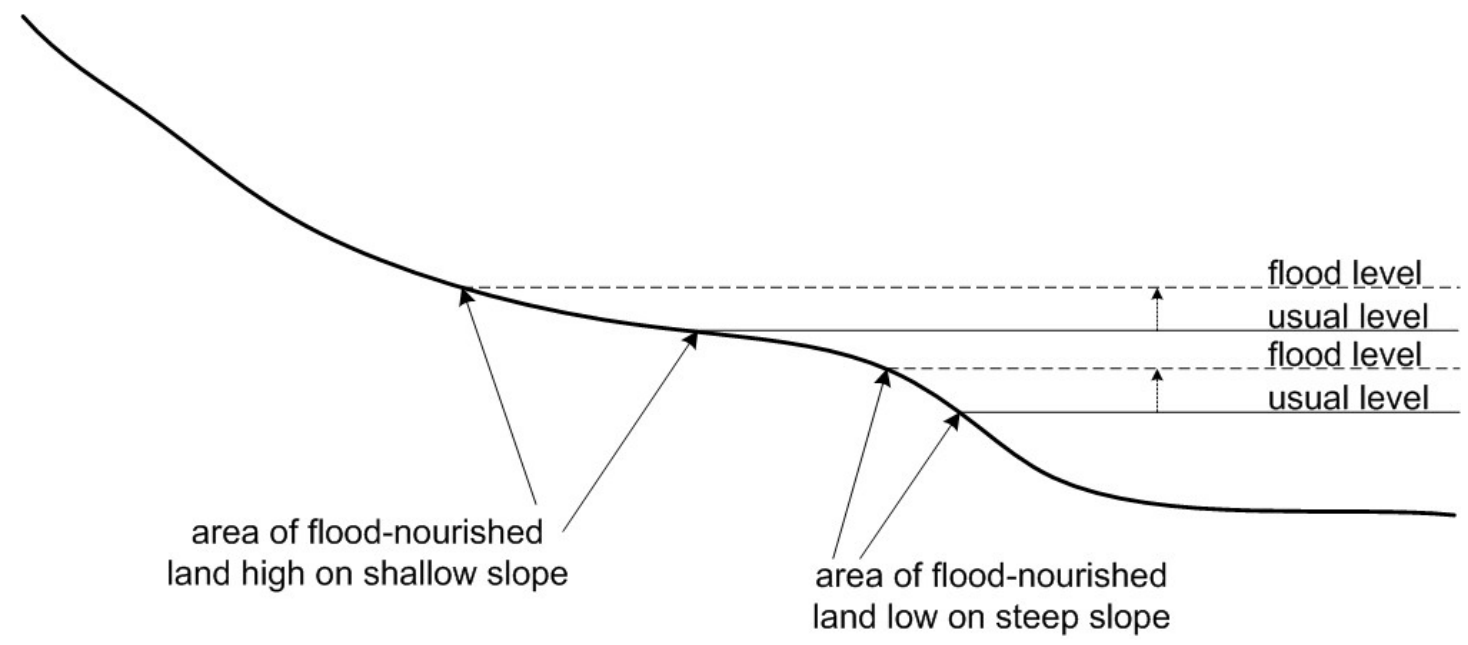

b) Area of fertile floodplain altering with change in slope

Figure 3. Processes of sedimentation in a lake and its floodplain. 
the cores DZ 13 and DZ 18, and further coring would be needed for verification.

A further point is that there are tentative indications $(\mathrm{Wu}$ et al. 1998: 8; Chen et al. 2008) that the depth of sediment accumulated in the last 2,000 years has been less than a metre, and cores in the middle of the lake reported by Zhu et al. (1989: Table 2.12, Figs 9.1, 10.1) show that strata at depths of $1 \frac{1 / 2}{2}$ metres date back to much earlier than $2,000 \mathrm{BP}$. Since the deepest part of the lake is currently only about 5.7 metres, and if indeed the level during the Wangjiadun occupation was 3 to 5 metres lower than today, it may be that the deepest part of the lake was not much more than 2 to $4 \frac{1}{2}$ metres. This suggests that the Wangjiadun culture was adapted to a swampy environment, with a relatively small lake at the centre.

\section{THE DIAN CULTURE}

The 'Dian Culture' is currently defined by the spatiotemporal distribution of distinctive artefacts recovered as early as the 1930s (Dewall 1967: 10; Chiou-Peng 2008: 334), and later excavated from dozens of tombs excavated since 1955 (Zhang et al. 1983: 19). Among these artefacts are what are known as the Dian Bronzes, characterised by cast bronze figures and scenes of everyday life, providing a tantalizing glimpse of a complex and artistically sophisticated society (Yao 2005; Chiou-Peng 2008). Pirazzoli-t'Serstevens (1989: 135 ; 1996-1997) has suggested that the period covered by tombs examined from the major elite cemeteries, where many of the bronzes have been unearthed, can be dated to within the period $250 \mathrm{BCE}$ to $50 \mathrm{CE}$.

Sima Qian ([145-ca. 86 BCE]1993: Shi ji 116, 253), Grand Historian of the Western Han Dynasty (206 BCE$8 \mathrm{CE}$ ), noted that the Dian Kingdom was one of the most important polities among those of the 'southwestern barbarians'. He stated that this kingdom was at Dianchi Lake, which had a perimeter of $300 \mathrm{li}$ and several thousand [square] $l i$ of rich flat land (Qian [145-ca. 86 BCE] 1993: 254).

\section{Dianchi Lake}

As a participant in the campaign to incorporate the southwestern areas into China (Watson 1958: 48, note 49), Sima Qian presumably saw the Kunming area and visited Dianchi Lake, so his information might have some factual basis. Indeed, the DEM for Dianchi Lake gives the perimeter as about $140 \mathrm{~km}$. During the Western Han Dynasty, one li was equal to $0.49 \mathrm{~km}$ (Needham and Wang 1954: 27, note d), so that the shoreline is about $280 \mathrm{li}$, close to what Sima Qian recorded. However, when we measure the area of land with slope less than $3 \%$, we get only about $290 \mathrm{~km}^{2}$, so with $1 \mathrm{li}^{2}$ equal to $0.24 \mathrm{~km}^{2}$, the flat land would have been $1,250 \mathrm{li}^{2}$, rather than several thousand. Moreover, this was probably not all fertile.

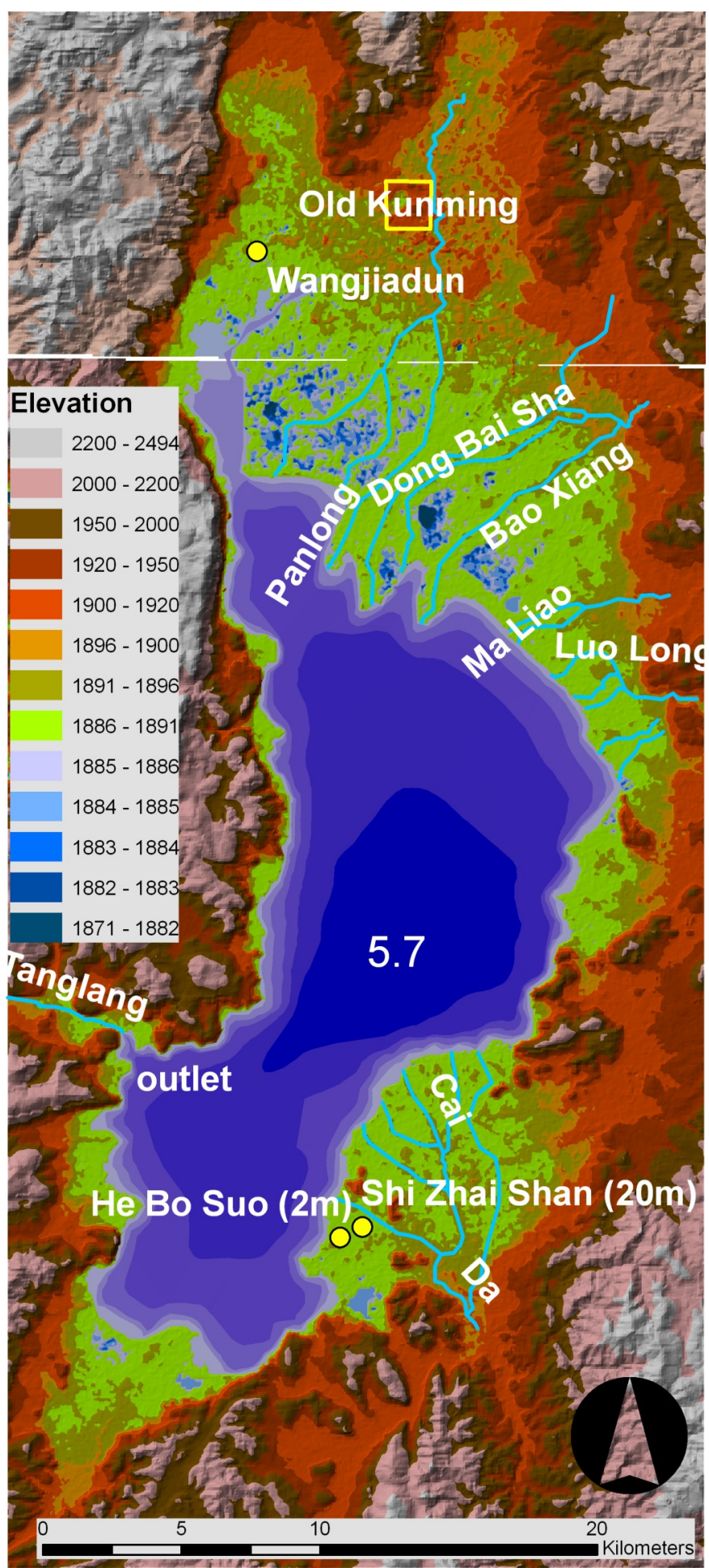

Figure 4. Dianchi Lake: flood-prone areas in light green. Areas away from the lake in blue are below today's lake level. 'Flat' land can be found as high as about $1920 \mathrm{~m}$. 


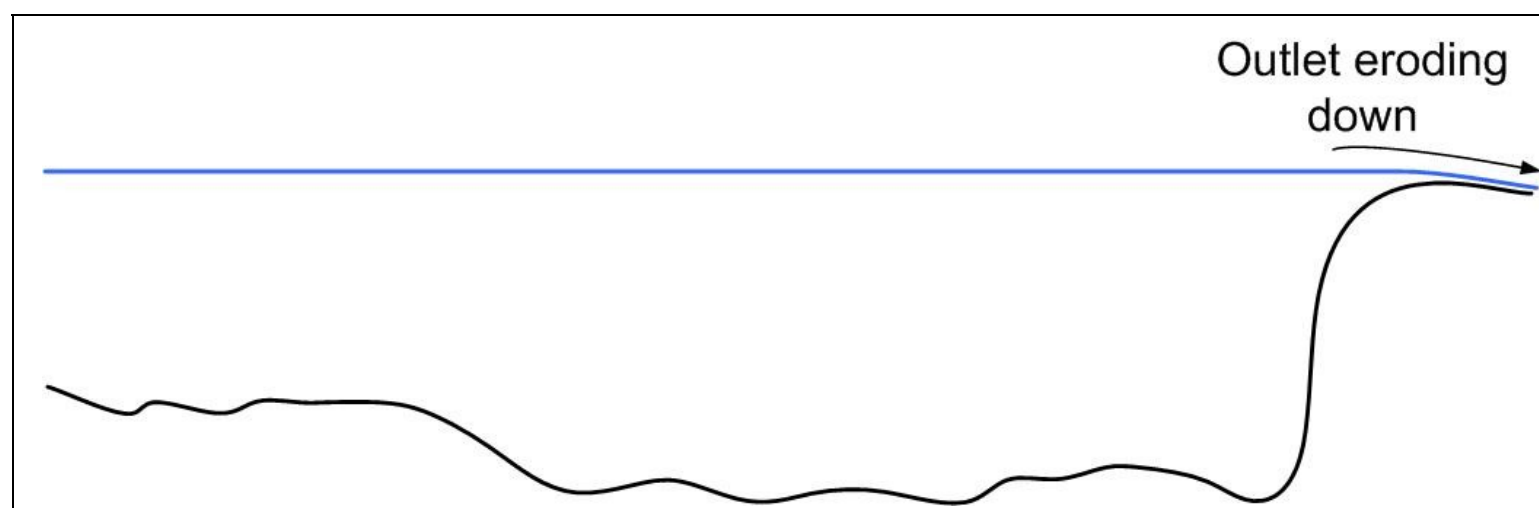

a) $12,000 \mathrm{BP}$ to 4,500 BP: lake level higher than today. Water level drops, perhaps because of outlet eroding.

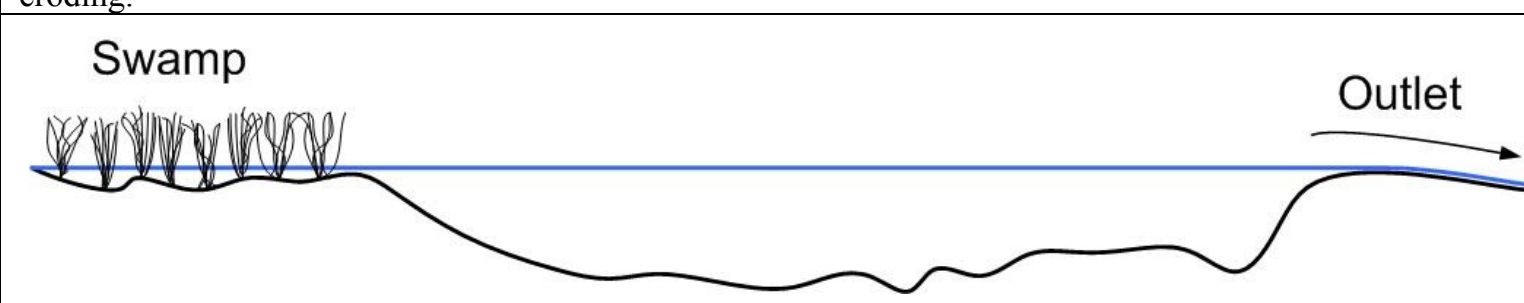

b) 4,500 BP: water level at northern end of lake shallow or swampy.

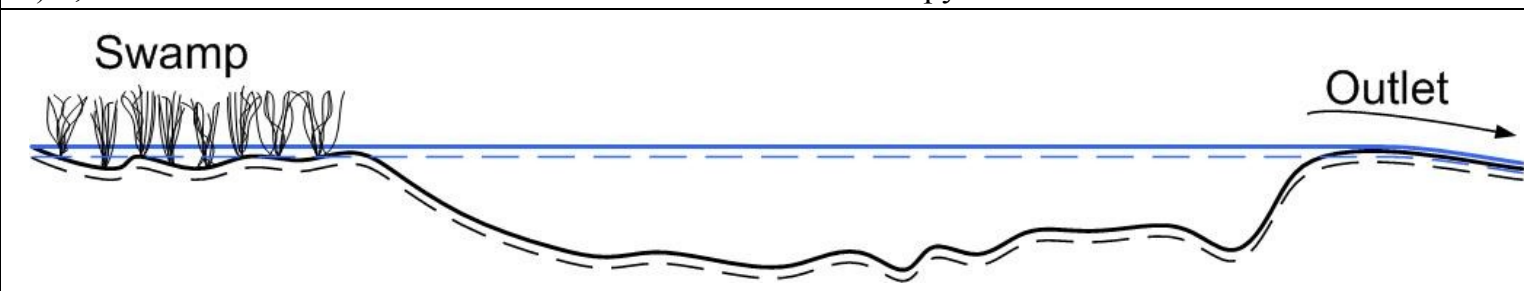

c) 4,500 BP to 1,500 BP: slow siltation at about same rate as sedimentation of outlet.

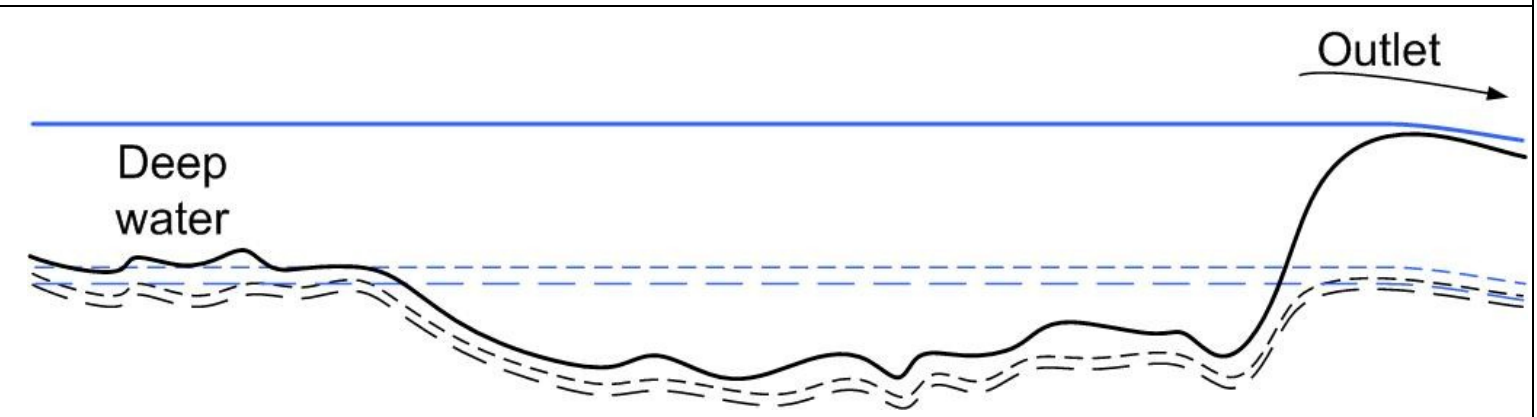

d) 1,500 BP to Qing dynasty: Repeated flooding to about $10 \mathrm{~m}$, requiring outlet to be dredged.

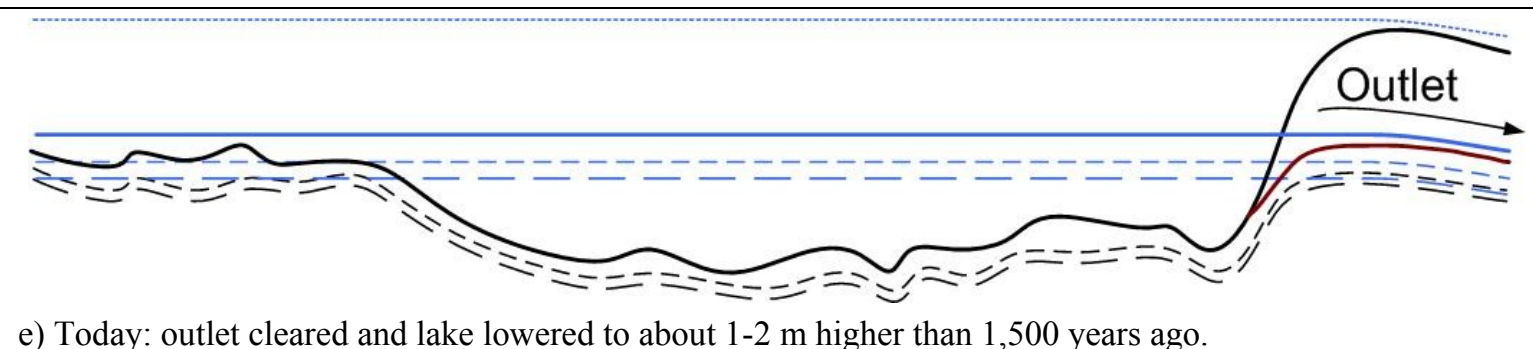

e) Today: outlet cleared and lake lowered to about 1-2 m higher than 1,500 years ago.

Figure 5. Schematic cross-section through Dianchi Lake at different times, as inferred from the available data. Northern end near Wangjiadun to left. Outlet at southern end of western side of lake. 


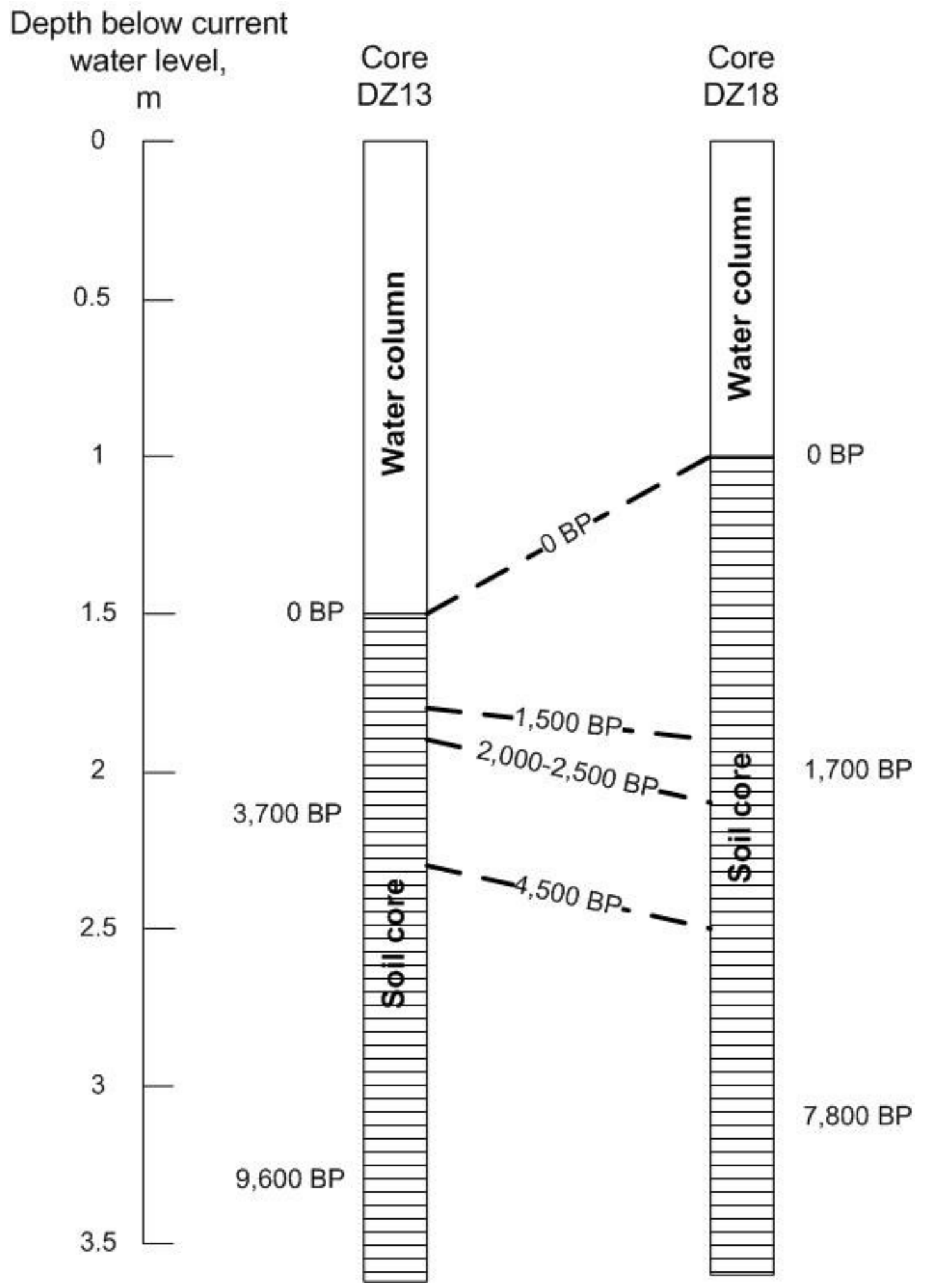

Figure 6. Profiles of Cores DZ13 and DZ18, showing indicative dates and depths. 

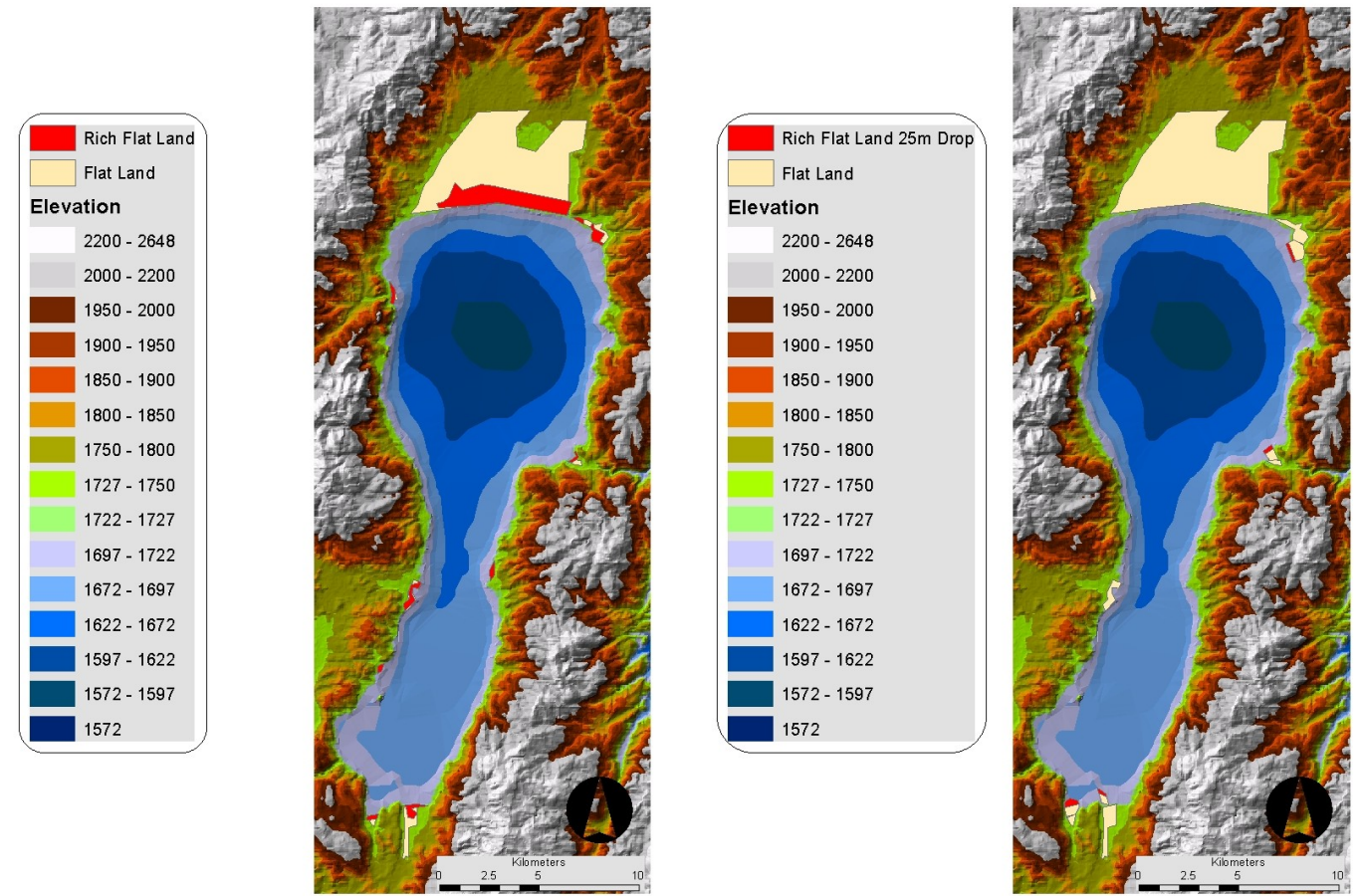

Figure 7. Fuxian Lake: flat land in yellow, flood-nourished land in red. (a) Left image. Today's water level. (b) Right image. Water level 25 metres lower.

The area of the catchment is about $2,900 \mathrm{~km}^{2}$, while that of the lake is roughly $300 \mathrm{~km}^{2}$ (Zhu et al. 1989: 5). By inspecting the topography using the DEM and Google Earth, we see that much of the land around the lake, particularly on the eastern side, is a series of inflowing deltas (Zhu et al. 1989: 404-470), with the banks of the watercourses traversing them rising as much as three metres above the rest of the alluvial lands (Figure 4). This is because floodwaters overflowing from these watercourses deposit sediment in their beds and on their banks, gradually raising their levels. Most of the coarse sediment carried by the watercourses will deposit close by, while the finer silt will normally be carried further onto the alluvial lands - which are mostly no more than five metres higher than the level of the lake. If the flat lands were rich before irrigation and terracing reportedly introduced by the Eastern Han (ca. 23 CE-220 CE) around 210 CE (Fang 1998: Vol 1, 57, juan 86; Vol. 1, 276, juan 10; Chiang 2009: 89-93), they would need to have been fertilised by floods from the lake or from sediment eroded from the catchment. We can therefore take, as a first approximation, the amount of fertile land to be roughly equal to the area that is no more than five metres above the level of the lake. With the DEM, it can be computed that there would have been about $175 \mathrm{~km}^{2}$ or $700 \mathrm{li}^{2}$ of land fertilised by silt.

If the Lake was three to four metres lower than today over 4,500 years ago, it could also have been lower during the period of the Dian culture. If so, it is possible that there was more land during the Dian period. To investigate this, the level of the lake was first estimated for this early period. About a kilometre from the southeast shore of the lake, an elite cemetery has been found on Shi Zhai Shan, a hill rising about 20 metres above the surrounding plain and a kilometre from the lake (Figure 4). A gold seal has been found in one tomb, possibly the one mentioned by Sima Qian (op. cit.: 258) as having been given to the Dian king by the Han emperor. There is much shell midden material on this hill. A shell at the top has been dated to 4,262 $\mathrm{BP} \pm 170$ (GC-639) well before the Dian period. Another shell, dated to $2,860 \mathrm{BP} \pm 110$ (GC-1035) has been found in a midden at the nearby village of $\mathrm{He}$ Bo Suo-about 500 metres from the lake - at a level 2 metres higher than the lake's water level (Zhu et al. 1989: 65). For reasons not entirely clear, Zhu and others (1989: 106) argue that the shells around Dianchi Lake, together with soil and artefacts from Neolithic sites on higher ground, indicate that in the period from 4,000 BP to 2,500 BP, the Lake was about five metres higher than today. However, if we assume that the He Bo Suo middens were built mainly on land, the level of the lake must have been no higher than two metres above the current level. Further, Figure 6 also indicates that from 2,500 BP to 2,000 BP, the period of the Dian, the lake was perhaps two metres lower than today. It must be stressed again that this conclusion is 


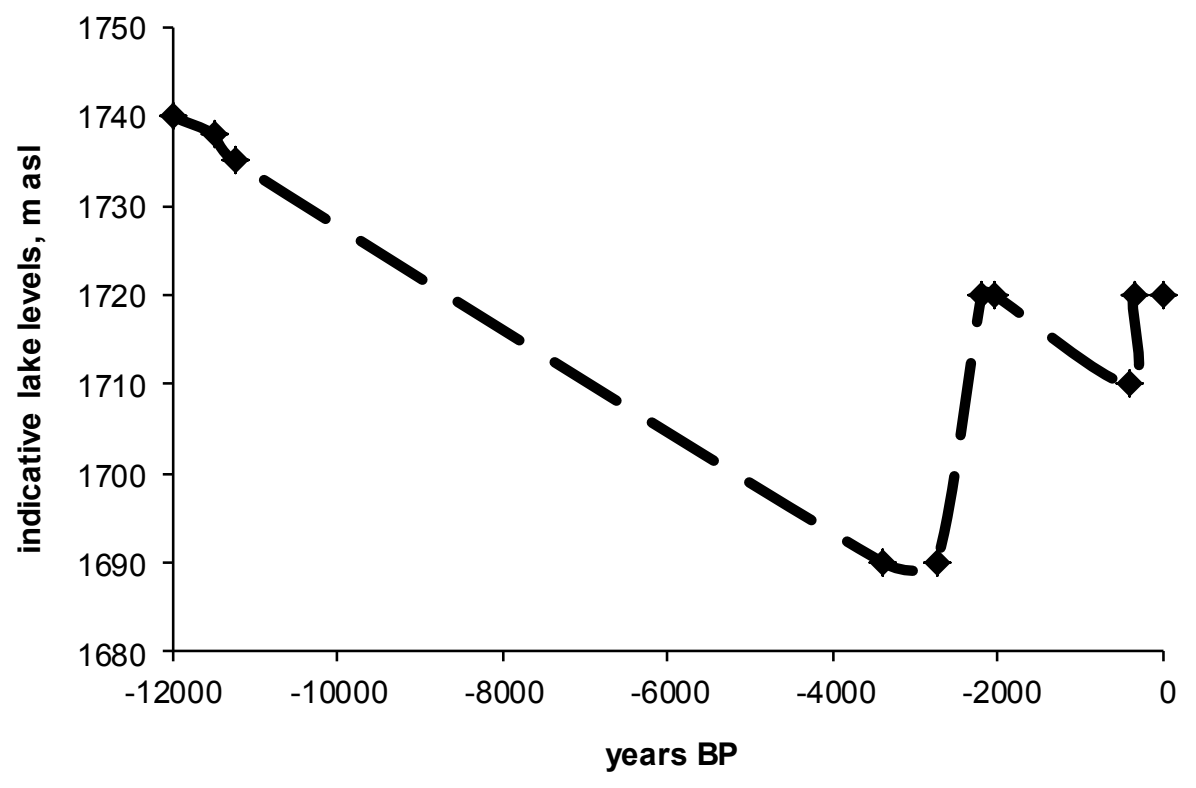

Figure 8. Fuxian Lake levels over time

based primarily on the cores DZ 13 and DZ 18, so additional coring and dating would be desirable to check this.

While additional dating of shells from Shi Zai Shan and He Bo Suo would also be desirable, the fact that the middens are there gives some support for the Lake being closer to these locations during their respective periods of deposition. Shell middens are usually located adjacent to aquatic environments (Stein 1992: 1). As Waselkov (1987: 114-115) points out, molluscs are small packages of meat in heavy inedible shells. This sets limits to how far they will be transported live from harvesting locations, as there is only a small calorific pay-off to be gained by expending energy on their transport. A number of additional factors can also influence the distance of a shell midden from the original resource procurement site (Meehan 1982: 159-161; Waselkov 1987:115-118; Bailey and Parkington 1988: 2-4; Parkington et al. 1988: 22-24). These include comfort and safety of the deposition site; seasonal, tidal and environmental fluctuations affecting availability of different species; social and biological imperatives; and availability of alternative foods. Extreme cases are on Pacific Islands, where middens are up to four kilometres from a coast, or hundreds of metres above the shoreline (Allen et al. 1988: 708; Allen et al. 1989: 550). On some (e.g. Solomon Islands), the deposition of shell middens on hilltops inland from the coast might be explained as security against historically documented raiding and warfare, which decimated large numbers of the population and in some instances entire clans (Melissa Carter pers. comm., 2010). Thus determining whether the deposition of a shell midden was originally close to a coast, lake or river requires an archaeological study as well as consideration of a range of environmental, economic and cultural evidence (Claasen 1991: 283-286).

John Miksic (pers. comm., 2009) suggests that for lacustrine settlements it is normally more cost-effective to trade rather than to raid, since lake-based raiders could not readily escape retribution by fleeing. Further, although some Dian bronzes depict scenes of land-based warfare, it is felt that such events were episodic and should not normally be used to explain substantial middens far from the shoreline. Thus it is hypothesised that the Dian Lakes middens may have formed relatively close to the shellfish procurement sites. If so, midden sites elevated above the current surrounding plain, such as at Shi Zhai Shan and He Bo Suo, may have been on islands surrounded by shallow water, even if the level of Dianchi Lake was lower than today, as indicated above. The fact that these two elevated sites are now surrounded by land, even though the Lake should now be two metres higher than at the time of the Dian, could be because this area may be part of the Lake reclaimed since at least the Ming Dynasty (1368-1644) (Fang 1998: vol 3, 390391 , vol 6,148$)$. In addition, there has been much erosion in the hills and consequently sedimentation in the floodplain, following the introduction of terracing in the $3^{\text {rd }}$ century CE. 

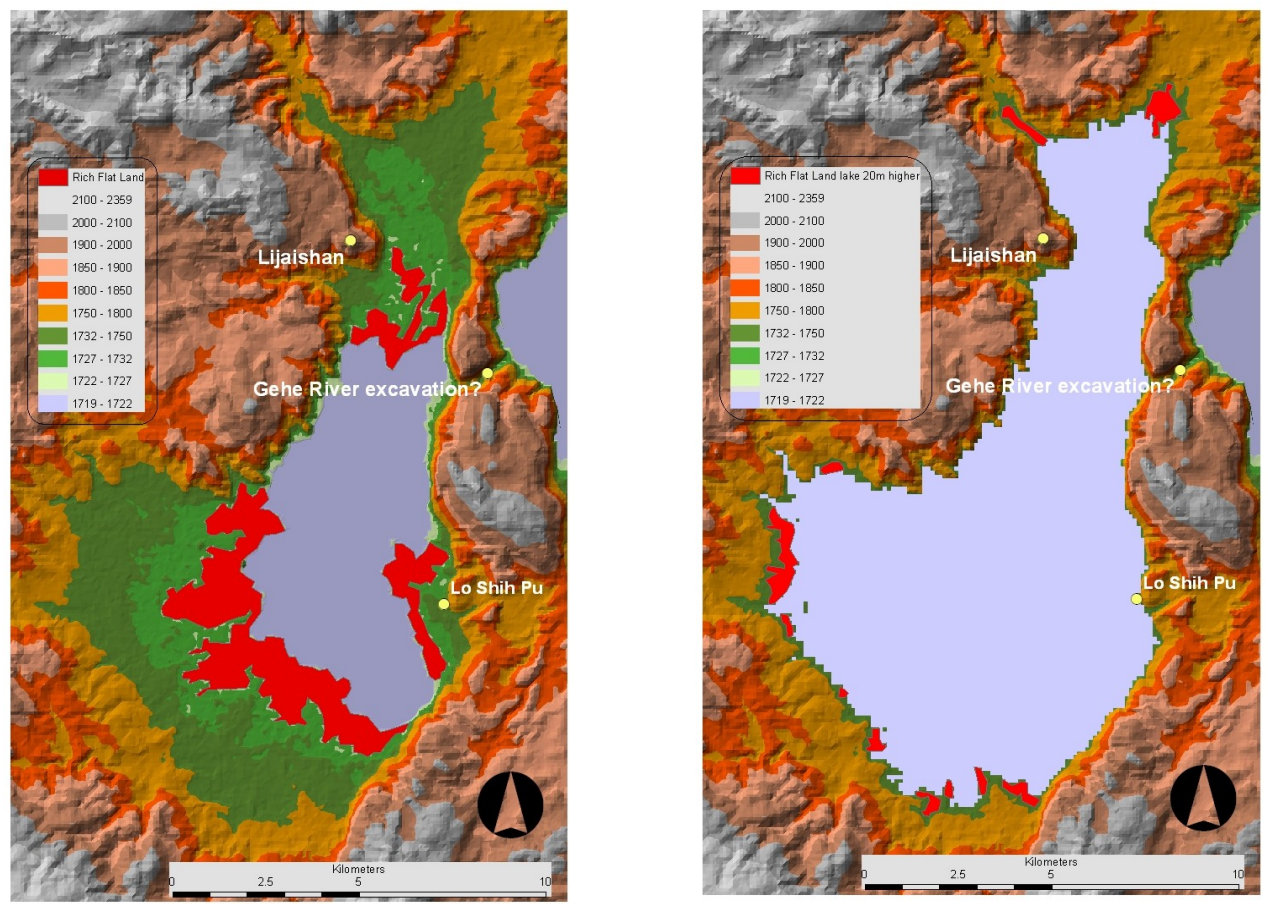

Figure 9. Xingyung Lake: flat land in yellow, flood-nourished land in red. (a) Left image. Today's water level. (b) Right image. Water level 20 metres higher.

While well-maintained terraces tend to reduce erosion, population pressures can lead to poor maintenance so that the terraces actually accelerate soil loss, and hence sedimentation and progradation along the shoreline. This appears to have occurred around Dianchi Lake (Whitmore et al. 1994: 68). Using the DEM to estimate this area of land with the Lake $2 \mathrm{~m}$ lower, one finds that there could have been another $80 l i^{2}$ of fertile land, bringing the total to $800 l i^{2}$.

It might be noted in passing that if Shi Zhai Shan was an island during the Dian period, the elite cemetery on it would have looked out on water to the east.

\section{Fertile land around other lakes}

It is possible that the fertile land around the other Dian lakes figured into Sima's assessment, and we can examine this. There are, of course, the floodplains of nearby river valleys that could also be counted, but given the hilly nature of the surrounding area, their total areas should not make a significant difference. The next largest lake is Fuxian (Figure 7). It is much deeper than Dianchi Lake, by as much as 155 metres ( $\mathrm{Yu}$ et al. 2001: 222). There are indications from palynological studies of this lake (Yu et al. 2001: 206-210) that there have been large fluctuations in water level over time (Figure 8). The lake may have been 20 metres higher about 12,000 years ago, and it dropped over the next 8,000 years to at least 30 metres below its current level ( $\mathrm{Yu}$ et al.
2001: 208). The steepness of the outlet valley suggests that this may have been a result of erosion of the outlet. Then, at around 2,700 BP, apparently just prior to the Dian period, it began rising sharply and reached today's level at around 2,200 BP. In view of the steep slopes to the north and south of the outlet, this may have been caused by a landslide in this period, blocking the outlet. The level may have dropped slightly at around $400 \mathrm{BP}$, then rose and remained at the level seen today.

The curve in Figure 8 is based on a small number of radiocarbon dates (Zhu et al. 1989: 275; Yu et al. 2001: 206210 ), and will also need to be verified. Nevertheless, we can say that there are intriguing indications that the water level was much lower than today. Applying the same calculations as above, we can determine that the amount of flat land is $130 \mathrm{li}^{2}$. The land subject to flooding--taken again as up to five metres above the level of the lake, even though detailed calculations could show it to be a little higher or loweramounts to only about $40 l i^{2}$ (Figure 6a). With the water level 25 metres lower, the 'flood-prone' land, instead of increasing, actually decreases to only $3 \mathrm{li}^{2}$ (Figure 6b), because the land below the current shoreline is steeper. This means that the amount of fertile land was probably less than today. We can conclude that the well nourished land at this lake did not make a significant contribution to the total. 


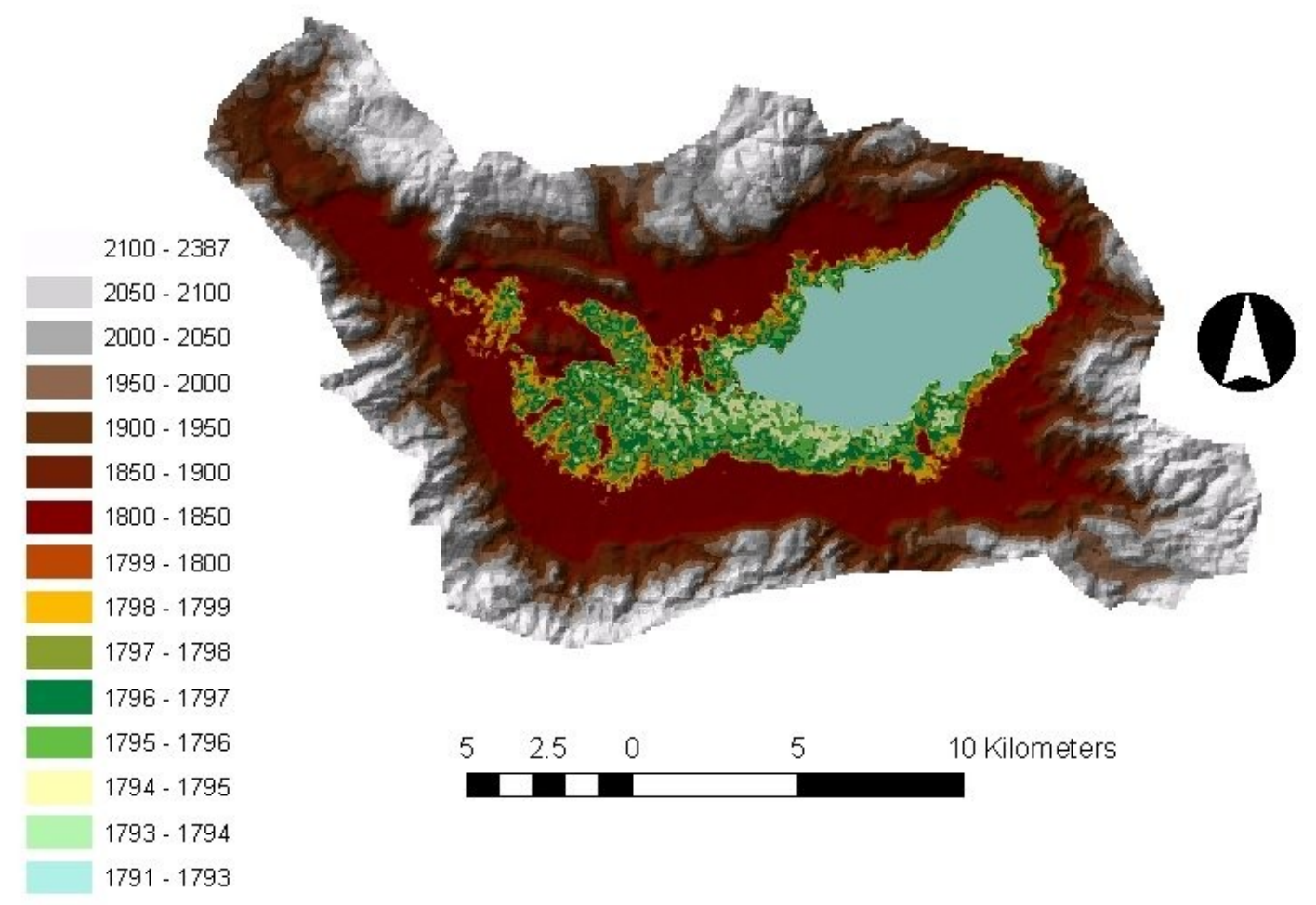

Figure 10. QiLu Lake 'natural' elevations from SRTM 'adjusted' data. In reality, lake is artificially about four metres higher than its natural level.

Xingyun Lake is another possible contributor to the total. An elite cemetery was found at Lijiashan, over two kilometres from the lake. The lake has about $255 l i^{2}$ of flat land, with $70 l i^{2}$ of flat land in the first five metres above the current level of the lake. However, it appears that the level of this lake has been much higher. The outlet of the lake, also known as the Ge River, flowed into Fuxian Lake until recently; it has been closed off to protect Fuxian Lake from the polluted waters of Xingyun Lake. In 1923, the Ge River was lowered two metres and in 1956 another one metre to reduce flooding (Whitmore et al. 1994: 68). A Kuomintang stele at the inlet to the Ge River states that the lake had flooding problems which were addressed in the Ming and Qing dynasties (1368-1911), and that the outlet channel was lowered by about two metres in the period 1933-1935. Thus, there has been a history of lowering of the Ge River since at least the Ming period.

There is a midden at Lo Shih $\mathrm{Pu}$, about one kilometre from the lake, where the gently-sloping land suddenly becomes quite steep. If the midden formed near the shoreline at the time, the level of the lake would have been about 20 metres higher than today, and Mount Lijia would have been at the water's edge - and perhaps, as at the Shizhaishan cemetery, also looking out over water. At this level, the 'flood-prone' flat land (ie. to five metres above the lake) is reduced from the $70 l i^{2}$ of today to only about $15 l i^{2}$ (Figure 9). If this lake was roughly 20 metres higher than today during the Dian period, it too would not have provided much additional fertile land.

Qi Lu Lake is similar to Xingyun Lake in size. Using the DEM (Figure 10) to estimate the area that is taken to be flood prone (up to five metres above the lake), we obtain a result of about $38 \mathrm{~km}^{2}$, or $160 \mathrm{li}^{2}$. This again would not represent a significant additional amount of rich flat land. The total flat land may amount to $280 \mathrm{li}$.

In all, these latter three lakes might together have provided between $200 l i^{2}$ and $300 l i^{2}$ of fertile terrain. The total, including Dianchi Lake, is about 1,000 $\mathrm{li}^{2}$. The total flat land, regardless of whether it is flood-prone or not, is about 1,900 $\mathrm{li}^{2}$. Perhaps, Sima Qian saw the extent of flat lands surrounding these lakes and assumed that all this terrain was well nourished, and not just those areas subject to flooding.

Moreover, it is reasonable to posit that these lands may not have been the only prime source of wealth. It could be that trade featured strongly with the Dian, as suggested by Allard (1998: 329), and as evidenced, for example, by the stores of cowry shells found in the elite cemeteries (Pirazzolit'Serstevens 1992; Chiou-Peng 2008: 35-39). Other sources 
of riches--such as bronze, gold and silver (Allard 1998: 331, 339)--could likewise have been important.

A further inference is that if the area of fertile land was not extensive, the population may not have been large. The socio-economic implications of a relatively small population might be explored further using models of population density and agricultural output for the area (e.g. Hassan 1981). A range of agricultural productivities would need to be modelled, because of the limited information available for pre-modern China (Elvin 2004: 208-209).

\section{FLOODING OF DIANCHI LAKE}

The presumption from the historical record has been that the accelerated soil erosion from the time of the Eastern Han dynasty may have led to siltation of the outlet of Dianchi Lake (Figure 4), starting around 1,500 BP, causing its level to rise more quickly than before (Sun et al. 1986: 464). By $1220 \mathrm{CE}$, the outlet is said to have been blocked to such an extent that the waters of the lake surrounded Kunming on three sides (Zhu et al. 1989: 106). Using the DEM, we can see that this would be possible once the level of the lake rose about 10 metres. Two thousand men are said to have worked for three years to alleviate the flooding (Fang 1998: Vol. 3, 267), but this flooding recurred repeatedly and, around $1501 \mathrm{CE}$, several tens of thousands of soldiers and citizens laboured to lower the level of the lake once more. They even undertook fire-setting (Fang 1998: Vol. 6, 125, juan 2), a technique of heating the rock, then cooling it rapidly with water or vinegar to cause it to crack, making it easier to excavate (Needham and Wang 1954: 26). Despite this, the historical records suggest that the blockage at the outlet still had to be relieved many times during the Ming and Qing Dynasties (Zhu et al. 1989: 106; YGEC, 1998: v38, 9-28, 401 $-5)$.

Yet this presents us with a paradox. As discussed above, only one to two metres of sediment has accreted in the lake during this period, and the sediment that flows out of a lake is usually only a very small proportion of the sediment inflow (Whitmore et al. 1994: 68), since much drops to the bottom. In addition, the lowest part of a lake should have more sediment than most other areas, because of the effect of sediment focusing, whereby sediment depositing on the floor of a lake tends to flow downhill to the low point (Lehman 1975). Since the core described by Wu and others (1998: 5) was in the deepest part of the lake, it should follow that the depth of accumulation of sediment was less than one or two metres in other parts of the Lake, so the outlet could not have blocked up by 10 metres through sedimentary processes alone. Furthermore, there is no indication of any natural process which could have resulted in a blockage such as a landslide at the outlet, or in a resistance to flow such as the growth of dense vegetation. The upshot is that these impedances to flow were likely the consequence - in part at least - of human activity (Jim Irish, pers. comm., 2010). Discerning the nature of any such cultural changes might shed more light on the nature of the social or economic situation at the time.

\section{CONCLUSIONS}

Dianchi Lake appears to have been much higher than today, until about 12,000 BP. Some time after that, between $10,000 \mathrm{BP}$ and $4,500 \mathrm{BP}$, it dropped to a minimum level, perhaps three to five metres lower than today. This may have been when the Wangjiadun site was occupied, and not during the early Bronze Age, as has been suggested. Dianchi Lake seems to have been smaller and shallower than now, with the inhabitants adapted to a swampy environment.

By the time of the Dian culture (250 BCE to $50 \mathrm{CE})$, Dianchi Lake may have risen from its minimum to a level about two metres lower than today. Most of the rich flat land during the Dian period was around Dianchi Lake, but it amounted to perhaps $800 l i^{2}$ - or , together with the other major lakes, 1,000 $l i^{2}$-and not thousands, as recorded by Sima Qian. This suggests that not all the flat land he saw was fertile. If the amount of fertile lands around Fuxian, Xingyun and Qi Lu and some parts of Dianchi Lakes were relatively limited, they would have supported only small populations. This particularly applies to the areas around the two elite cemeteries at Shi Zhai Shan and Lijiashan. Knowing the extent to which the shallows around Dianchi Lake were subsequently reclaimed to provide farming land, and the depth to which the Ge River was excavated to mitigate flooding in Xingyun Lake could provide some additional perspectives on the relationships between the major population centres and these two elite cemeteries. A better understanding of the size of the population could also help improve our appreciation of the socio-political organisational structure within the Dian culture, particularly if agricultural production was not the dominant source of wealth, and trade and mining played a greater role.

The cause of the repeated impedances to flow at the outlet from Dianchi Lake starting from the $13^{\text {th }}$ century CE, and resulting in rises of up to 10 metres in the level of the lake, is not yet understood. Verification of these events through additional archaeological studies could provide indications of the nature of changes to the water environment from the time of the Eastern Han dynasty.

Two of the above suggestions - that the Wangjiadun settlement was established no less than 4,500 years ago, and that Dianchi Lake may have been about two metres lower than today at the time of the Dian culture - are based on the results from two cores. Further coring would be needed for verification. 


\section{ACKNOWLEDGEMENTS}

Thanks are due to Edna Wong, University of Sydney; Chiang Po-Yi, Australian National University; Chiou-Peng TzeHuey, University of Illinois at Urbana-Champaign; Melissa Clarke, University of Sydney; Aedeen Cremin, Australian National University; Damian Evans, University of Sydney; Robert French; Mitch Hendrickson, University of Sydney; Jim Irish, North China Water Engineering and Hydropower University; Jens Kiesel, Hydroc Consult; Eileen Lustig, University of Sydney; John Miksic, National University of Singapore; Dan Penny, University of Sydney; Tian Sheng, University of Sydney; Alice Yao, University of Toronto; and two anonymous reviewers.

\section{REFERENCES}

Allard, F.. 1998. Stirrings at the periphery: history, archaeology, and the study of Dian. International Journal of Historical Archaeology 2: 321-341.

Allen, J., C. Gosden, R.T. Jones, and J.P. White. 1988. Pleistocene dates for the human occupation of New Ireland, northern Melanesia. Nature 331: 707-709.

Allen, J., C. Gosden, and P.J. White. 1989. Human Pleistocene adaptations in the tropical island Pacific: recent evidence from New Ireland, a Greater Australian outlier. Antiquity 63: 548-561.

Bailey, G. and J. Parkington. 1988. The archaeology of prehistoric coastlines: an introduction. In J. Parkington and G. Bailey (eds.), The archaeology of prehistoric coastlines. Cambridge: The University Press.

Chen, R.Y., X.L. Song, S.T. Zhang, Z.X. Zhang, and W. Yang. 2008. Dianchi 700 nian lai qi hou bian hua yu ren lei huo dong de hu po huan jing xiang ying yan jiu (Dianchi Lake sediment records of climate changes and human activities in the past 700 years). Yanhu yanjiu (Journal of Salt Lake Research) 16: 7-12. (in Chinese).

Chiang, P.-Y. 2009. Archaeology of Ancient Yunnan: Sichuan influence in the transformation of the Shizhaishan culture, Saarbrücken, VDM Verlag Dr Müller.

Chiou-Peng, T.-H. 2008. Dian Bronze Art: its source and formation. Bulletin of the Indo-Pacific Prehistory Association. 28: 34-43.

CIAT-CSI. 2009. SRTM website [Online]. The CGIAR Consortium for Spatial Information (CGIAR-CSI). Available: http://srtm.csi.cgiar.org [Accessed 2009].

Claasen, C. 1991. Normative thinking and shell-bearing sites.
In M.B. Schiffer (ed.), Archaeological method and theory. Tucson: University of Arizona Press.

von Dewall, M. 1967. The Tien culture of South-west China. Antiquity 41: 8-21.

Elvin, M.J.D. 2004. The retreat of the elephants : an environmental history of China., New Haven, Yale University Press.

Fang, G. 1998. Yunnan Shiliao Congkan (The collection of Yunnan historical sources), Kunming, Yunnan Daxue Chubanshe.

Hassan, F.A. 1981. Demographic archaeology, New York, Academic Press.

Jarvis, A., H.I. Reuter, A. Nelson, and E. Guevara. 2008. Hole-filled seamless SRTM data V4 [Online]. International Centre for Tropical Agriculture (CIAT). Available: http://srtm.csi.cgiar.org [Accessed 2009].

Jiang, Z. 2002. 澛國探柲 Dian guo tan mi (Investigation into the Dian Kingdom), Kunming, Yunnan Jiaoyu Chubanshe.

Lehman, J. 1975. Reconstructing the rate of accumulation of lake sediment: the effect of sediment focusing. . Quaternary Research 5: 541-550.

Li., Y. and H. Wang. 1983. Kunming shi Xishan qu Wangjiadun fa xian qing tong qi (Bronzes discovered at Wangjiadun, Xishan District, Kunming City). Kaogu, 5: 479. (In Chinese).

Meehan, B. 1982. Shell bed to shell midden, Canberra, Australian Institute of Aboriginal Studies.

Needham, J. and L. Wang. 1954. Science and civilisation in China: Vol 4. Physics and physical technology: Pt. 3. Civil engineering and nautics, Cambridge, Cambridge University Press.

Parkington, J., C. Poggenpoel, B. Buchanan, T. Robey, T. Manhire, and J. Sealy. 1988. Holocene coastal settlement patterns in the western Cape. In J. Parkington and G. Bailey (eds.), The archaeology of prehistoric coastlines. Cambridge: The University Press.

Pirazzoli-T'Serstevens, M. 1989. The Dian culture: a problem of chronology, reviewed in report on First International Conference on ancient bronze drums and bronze cultures of Southern China and Southeast Asia, 9-17 October 1988. Arts asiatiques 44: 134-136. 
1992. Cowry and Chinese Copper Cash as Prestige Goods in Dian. In: GLOVER, I. (ed.) Southeast Asian Archaeology 1990: Proceedings of the Third Conference of the European Association of Southeast Asian Archaeologists. Hull: Center for SouthEast Asian Studies, University of Hull.

1996-1997. A Reassessment of the dating of two important cemeteries of the Tien Culture. In F.D. Bulbeck and N. Bernard (eds.), Ancient Chinese and Southeast Asian bronze age cultures : the proceedings of a conference held at the Edith and Joy London Foundation property, Kioloa, NSW : 8-12 February, 1988. Taipei: SMC Publishing.

Sima, Q. [145-ca. 86 BCE]1993. Records of the grand historian of China: Han Dynasty II, translated from Shi ji 116 Vol II Part 2 of Sima Qian by Burton Watson. New York, Revised edition, Columbia University Press.

Stein, J.K. 1992. The analysis of shell middens. In J.K. Stein (ed.), Deciphering a shell midden. San Diego: Academic Press.

Sun, X., Y. Wu, Y. Qiao, and D. Walker. 1986. Late Pleistocene and Holocene vegetation history at Kunming, Yunnan Province, southwest China. Journal of Biogeography 13: 441-476.

Walker, D. 1986. Late Pleistocene-early Holocene vegetational and climatic changes in Yunnan Province, southwest China. Journal of Biogeography 13: 477-486.

Wang, E., B.C. Burchfiel, L.H. Royden, L. Chen, J. Chen, W. Li, and Z. Chen. 1998. Late Cenozoic XianshuiheXiaojiang, Red River, and Dali fault systems of southwestern Sichuan and central Yunnan, China, Boulder, Colo., Geological Society of America.

Waselkov, G.A. 1987. Shellfish gathering and shell midden archaeology. In M.B. Schiffer (ed.), Advances in archaeological method and theory. San Diego: Academic Press.

Watson, B. 1958. Ssu-ma Ch'ien : grand historian of China. , New York, Columbia University Press.

Whitmore, T.J., M. Brenner, D.R. Engstrom, and S. Xueliang. 1994. Accelerated soil erosion in watersheds of Yunnan Province. Journal of Soil and Water Conservation 49: 67(6).

Wu, Y.H., R.J. Wu, B. Xue, J.L. Qian, and J.Y. Xiao. 1998. $13 \mathrm{kaBP}$ yi lai Dianchi di qu gu huan jing yan hua (Paleoenvironmental evolution in Dianchi lake area since 13ka BP). Hu po ke xue (Journal of Lake Sciences) 10: 5 -9. (in Chinese).

Yao, A. 2005. Scratching beneath iconographic and textual clues: A reconsideration of the social hierarchy in the Dian culture of Southwestern China. Journal of Anthropological Archaeology 24: 378-405.

YGEC. 1998. 云南省志 Yunnan Sheng zhi (Yunnan Gazeteer), Kunming, Yunnan ren min chu ban she (Yunnan People's Publishing Company). Yunnan Sheng di fang zhi bian zuan wei yuan hui (Yunnan Gazeteers Editorial Committee) (in Chinese).

Yu, G., S.P. Harrison, and B. Xue. 2001. Lake status records from China: Data Base Documentation, Jena. MaxPlanck-Institut für Biogeochemie.

Zhang, Z., T.C. Sun, and D.-D. Wang. 1983. Introduction to the bronzes of Yunnan. In J.F. Rawson (ed.), The Chinese bronzes of Yunnan. London: Sidgwick and Jackson in association with Cultural Relics Publishing House, Beijing.

Zhu, H.H., Y.T. Chen, W.M. Pu, S.M. Wang, and D.-D. Zhuang. 1989. Yunnan duan xian hu po huan jing yu chen ji (Environments and sedimentology of fault lakes of Yunnan). Beijing, Ke xue chu ban she (Science Press) (in Chinese). 